\title{
Modelo de análise de regressão periódica da precipitação mensal, da bacia atlântico sudeste, no Estado do Paraná(1)
}

\author{
Emilson França de Queiroz ${ }^{(2)}$, Reinaldo Joaquim Bezerra da Silva ${ }^{(3)}$ e Maria Cristina Neves de Oliveira ${ }^{(4)}$
}

Resumo - Este trabalho consistiu da realização da análise de regressão periódica dos totais mensais de precipitação de oito localidades do Estado do Paraná. Foram derivados modelos matemáticos que descrevem o transcurso desta variável, considerando um período de doze meses. A análise foi desenvolvida através da álgebra matricial e realizada a expansão em série de Fourier de uma função f(t), periódica e definida para o intervalo. Os dados originais foram ajustados para meses de 30 dias, transformados para normalizar a distribuição. Posteriormente foram determinados todos os componentes harmônicos das funções referentes a cada um dos oito locais. Após a verificação da normalidade dos componentes harmônicos, realizou-se a análise de variância, o que permitiu identificar os componentes harmônicos significativos, que foram escolhidos para fazer parte da equação de regressão correspondente a cada local. Estas equações explicaram de $89,56 \%$ a $99,60 \%$ da variação devida a meses, considerando o conjunto das localidades estudadas. A probabilidade de ocorrência de um ano conforme o modelo, expressa em porcentagem, variou de $14,19 \%$ a $68,42 \%$, enquanto a probabilidade de ocorrência de um ano conforme a média variou de $0,02 \%$ a $1,87 \%$.

Termos para indexação: métodos climatológicos, modelos matemáticos, dados meteorológicos.

A model for monthly rainfall periodic regression analysis, of the southeast Atlantic basin, on Paraná State

\begin{abstract}
This study deals with the periodic regression analysis of the monthly total rainfall, for eight locations in the State of Paraná, Brazil. Mathematical models which describe the course of this variable observing a period of twelve months were applied. The analysis was developed by means of matrice algebra and the expansion in Fourier series of a function $\mathrm{f}(\mathrm{t})$, periodic and defined for intervals. The original data were adjusted for 30-day months and all harmonic components of the functions referring to each of the eight locations were determined. After testing for normality of the harmonic components, an analysis of variance was made, which made it possible to identify the significant harmonic components which were chosen to make up part of the regression equation corresponding to each location. These equations explain $89.56 \%$ up to $99.60 \%$ of the variation due to months, for the whole set of studied locations. Probability for occurrence of a year in accordance to the model, in percentage, ranges from $14.19 \%$ to $68.42 \%$, while probability for occurrence of a year adjusted to mean, ranges from $0.02 \%$ to $1.87 \%$.
\end{abstract}

Index terms: climatological methods, mathematical models, meteorological data.

\section{Introdução}

As exigências hídricas constituem o principal fator a ser atendido para a obtenção de altas produtivi-

\footnotetext{
(1) Aceito para publicação em 20 de dezembro de 2000.

(2)Embrapa-Sede, Dep. de Pesquisa e Desenvolvimento, Caixa Postal 040315, CEP 70770-901 Brasília, DF. E-mail: emilson@sede.embrapa.br

(3)Embrapa-Sede, Secretaria de Administração Estratégica E-mail: rjbs@sede.embrapa.br

(4) Embrapa-Centro Nacional de Pesquisa de Soja, Caixa Postal 231, CEP 86001-970 Londrina, PR. E-mail: mcneves@cnpso.embrapa.br
}

dades e da estabilidade do rendimento ao longo dos anos, na maioria das espécies cultivadas em áreas tropicais e subtropicais. Conseqüentemente, as anomalias da precipitação constituem a principal causa das oscilações da produção e da produtividade anual destas culturas. Na região sul do Brasil, por exemplo, podem ser esperadas reduções significativas na produção de grãos, devido à seca, três vezes a cada dez anos (Mota, 1983). Assim, o conhecimento do transcurso anual da precipitação mensal e de sua variabilidade contribuem para o planejamento de medidas de redução dos impactos das anomalias da precipitação sobre a produção agropecuária. Os conhe- 
cimentos sobre o regime de chuvas também contribuem para a tomada de decisões em outras áreas estratégicas para o desenvolvimento econômico e social do País, como, por exemplo, a geração de energia elétrica, defesa civil e algumas atividades industriais.

Entretanto, no Brasil, os três níveis geopolíticos do Estado e a iniciativa privada encontram-se, freqüentemente, em situação de crônica improvisação diante da ocorrência de anomalias meteorológicas de grande escala. Em razão do conhecimento insuficiente das probabilidades de ocorrência de anos atípicos, é postergado o planejamento de longo prazo, principalmente para amenizar o impacto destas anomalias sobre a produção agrícola e sobre as populações instaladas em áreas urbanas ou rurais com risco de enchentes. Diante destas anomalias de grande escala e intensidade, as medidas de caráter operacional, adotadas na propriedade, na maioria das vezes não são eficientes para reduzir o impacto sobre a produção e a produtividade. Neste caso, são necessárias medidas de caráter estratégico que visem a redução do impacto das anomalias de grande escala sobre a produção, o abastecimento e a comercialização. Medidas deste tipo são, por exemplo, a diversificação de culturas, diversificação de cultivares e tecnologias, adotadas no âmbito da propriedade ou da região, bem como a diversificação de ambientes para a instalação de determinada cultura. Além dessas medidas, adotadas na fase de planejamento e diretamente relacionadas com a produção, poderão ser tomadas medidas relacionadas ao abastecimento e à comercialização, como o monitoramento e previsão de safras, dimensionamento de estoques regionais e nacionais de alimentos, seguro agrícola, e outros. O estabelecimento de tais medidas, para ser realizado com o máximo de eficiência física e econômica, também exige que sejam conhecidas as probabilidades de ocorrência de anos anômalos, precedidas de sua definição meteorológica e estatística.

Entende-se que, ao ser atingido um volume suficiente de informações neste sentido, será possível aumentar a capacidade dos três níveis geopolíticos do Estado e da iniciativa privada para reduzirem o impacto de anomalias meteorológicas de grande escala sobre a economia e sobre a sociedade como um todo.

Pesq. agropec. bras., Brasília, v. 36, n. 5, p. 727-742, maio 2001
É no sentido de contribuir para a formação do conhecimento básico de tais medidas que deve ser analisado estatisticamente o transcurso anual da precipitação mensal, bem como a ocorrência das anomalias de grande escala. Para o atendimento a estes objetivos, poderá ser utilizada, entre outras análises, a de regressão periódica.

Conrad \& Pollak (1950) utilizaram a análise de regressão periódica no estudo de fenômenos climáticos que apresentam tendência quase periódica. Apresentaram o método e a marcha de cálculo, e o exemplificaram por meio de sua aplicação a um fenômeno de transcurso anual, e outro, com transcurso diário. Fenômeno quase-periódico é aquele no qual o valor do elemento estudado não se reproduz exatamente a determinados intervalos constantes de tempo, como se a um processo estritamente periódico se superpusessem influências modificadoras de caráter aleatório, como no caso da precipitação mensal e de outras variáveis meteorológicas (Brooks \& Carruthers, 1953).

Bliss (1958) utilizou a análise de regressão periódica no estudo de variáveis climatológicas que apresentam tendência cíclica, pois considerou inadequado que as mesmas sejam descritas por uma regressão polinomial. Comprovou que, se os dados de observação variam simetricamente durante o ciclo, o fenômeno pode ser explicado por uma função senoidal. Nos casos em que a variação dos dados de observação não é simétrica, o fenômeno pode ser explicado pela síntese de várias funções senoidais de períodos diferentes.

Os fundamentos teóricos e o método de utilização da análise harmônica para o estudo de séries temporais oriundas de fenômenos quase-periódicos foram apresentados por Amaral (1968), que fez uma aplicação ao estudo de séries de dados de precipitação mensal de Pelotas, RS, e Morro Velho, MG. Estes resultados abrangem a realização das análises de variância dos contrastes e das amplitudes, as quais permitem selecionar os componentes harmônicos significativos que, para determinado nível de significância, devem fazer parte da equação de regressão representativa do transcurso do fenômeno, durante determinado período de tempo, que tenha significado físico. A aplicação deste método permitiu a determinação do transcurso anual da precipita- 
ção mensal, significativo para determinado nível de probabilidade, bem como sua variabilidade, possibilitando que as decisões relacionadas com a precipitação, não sejam tomadas apenas com base na média.

Posteriormente, foram realizados diversos estudos de séries temporais de precipitação mensal, utilizando este método (Amaral, 1975; Thiebaut, 1976; Pereira, 1978; Feltrin, 1980; Santos, 1984; Queiroz, 1988). Silva (1977) utilizou a análise de regressão periódica para estudar a precipitação pentadal em Pelotas.

Os objetivos deste trabalho foram derivar as equações de regressão periódica, do transcurso anual da precipitação mensal de oito localidades das zonas hidrográficas da vertente atlântica e do litoral do Estado do Paraná, e comparar os resultados do modelo com as médias da precipitação mensal das localidades estudadas.

\section{Material e Métodos}

Foram utilizados os totais mensais de precipitação observados durante o período que se estende de janeiro de 1960 a dezembro de 1990, em postos pluviométricos e nas estações climatológicas citados na Tabela 1 .

No Estado do Paraná, conforme a classificação de Köppen, apresentada por Godoy et al. $(1976,1978)$ e Corrêa et al. (1994), ocorrem os tipos climáticos Af, Cfb e Cfa. A Tabela 1 apresenta os tipos climáticos que ocorrem nos oito locais estudados neste trabalho.

\section{Modelo matemático}

Uma função $\mathrm{f}(\mathrm{t})$ é periódica, de período $\mathrm{T}>0$, se para todo t ocorrer:

$$
f(t \pm T)=f(t)
$$

ou ainda,

$f(t \pm n T)=f(t)$, sendo $n=0,1,2, \ldots \ldots$

As funções trigonométricas sen $\mathrm{t}$ e cos $\mathrm{t}$ são funções periódicas, de período $\mathrm{T}=360^{\circ}$, ou seja:

$\operatorname{sen}(t \pm n 360)^{\circ}=\operatorname{sen} t^{\circ}$

$\cos (t \pm n 360)^{\circ}=\cos t^{\circ}$, sendo $n=0,1,2, \ldots$.

A função, representada pela série trigonométrica de Fourier,

$f(t)=a_{o}+\sum_{j=1}^{\infty} a_{j} \operatorname{sen}\left(j \theta t+A_{j}\right)$

é periódica, de período $\mathrm{T}$, onde a freqüência angular é $\theta=360^{\circ} / \mathrm{T}$

Desenvolvendo-se (1), tem-se:

$f(t)=a_{o}+a_{1} \operatorname{sen}\left(\theta t+A_{1}\right)+a_{2} \operatorname{sen}\left(2 \theta t+A_{2}\right)+$ $\ldots \ldots . .+a_{j} \operatorname{sen}\left(j \theta t+A_{j}\right)+\ldots$

Budak \& Fomin (1973) consideram que esta função corresponde a uma soma de componentes senoidais, com freqüências distintas, sendo $\mathrm{T}$ um período comum a todos os componentes.

O componente senoidal com freqüência angular $\theta j=j \theta$ é o j-ésimo harmônico da função periódica. O primeiro

Tabela 1. Identificação, coordenadas geográficas, e tipo climático de estações e postos meteorológicos instalados em oito localidades das zonas hidrográficas do litoral e da vertente atlântica, no Estado do Paraná.

\begin{tabular}{|c|c|c|c|c|c|c|}
\hline \multirow[t]{2}{*}{ Código } & \multirow[t]{2}{*}{ Município } & \multicolumn{2}{|c|}{ Coordenadas geográficas } & \multirow{2}{*}{$\begin{array}{c}\text { Altitude } \\
(\mathrm{m})\end{array}$} & \multirow[t]{2}{*}{ Instituição } & \multirow{2}{*}{$\begin{array}{c}\text { Transfor- } \\
\text { mação }\end{array}$} \\
\hline & & Latitude & Longitude & & & \\
\hline \multicolumn{7}{|c|}{ Zona hidrográfica do litoral: sub-bacia 82; tipo climático Af de Köppen } \\
\hline 02548010 & Paranaguá & $25^{\circ} 31^{\prime}$ & $48^{\circ} 31^{\prime}$ & 5 & INEMET & 1,333 \\
\hline 02548003 & Antonina & $25^{\circ} 14^{\prime}$ & $48^{\circ} 45^{\prime}$ & 80 & DNAEE & 0,667 \\
\hline 02548000 & Morretes (1) - Morretes & $25^{\circ} 28^{\prime}$ & $48^{\circ} 50^{\prime}$ & 8 & DNAEE & 1,000 \\
\hline 02548002 & Morretes (2) - Véu da Noiva & $25^{\circ} 26^{\prime}$ & $48^{\circ} 57^{\prime}$ & 680 & DNAEE & 0,333 \\
\hline \multicolumn{7}{|c|}{ Zona hidrográfica da vertente atlântica: sub-bacia 81; tipo climático Cfa de Köppen } \\
\hline 02548001 & Campina Grande do Sul & $25^{\circ} 10^{\prime}$ & $48^{\circ} 53^{\prime}$ & $750^{(1)}$ & DNAEE & 0,1665 \\
\hline 02449000 & Adrianópolis & $24^{\circ} 39^{\prime}$ & $49^{\circ} 00^{\prime}$ & 180 & DNAEE & 1,000 \\
\hline 02449007 & Cerro Azul - Turvo & $24^{\circ} 45^{\prime}$ & $49^{\circ} 20^{\prime}$ & 400 & DNAEE & 0,667 \\
\hline 02449006 & Cerro Azul - Balsa & $24^{\circ} 48^{\prime}$ & $49^{\circ} 17^{\prime}$ & 270 & DNAEE & 1,000 \\
\hline
\end{tabular}

${ }^{(1)}$ Tipo climático $\mathrm{Cfb}$ 
harmônico, também chamado onda fundamental, tem o mesmo período e a mesma freqüência que a função.

Os coeficientes $a_{j}\left(a_{j}>0\right)$ e $A_{j}\left(0^{\circ}<A_{j}<360^{\circ}\right)$ são denominados, respectivamente, amplitude harmônica e ângulo fase.

Desenvolvendo o seno da soma de cada um dos harmônicos em (2), tem-se:

$f(t)=a_{0}+a_{1}\left(\operatorname{sen} \theta t \cos A_{1}+\operatorname{sen} A_{1} \cos \theta t\right)+a_{2}(\operatorname{sen} 2 \theta t$ $\left.\cos A_{2}+\operatorname{sen} A_{2} \cos 2 \theta t\right)+a_{j}\left(\operatorname{sen} j \theta t \cos A_{j}+\operatorname{sen} A_{j}\right.$ $\cos j \theta t)$.

Fazendo:

$$
\begin{aligned}
& a_{1} \operatorname{sen} A_{1}=p_{1} \quad a_{1} \cos A_{1}=q_{1} \\
& a_{2} \operatorname{sen} A_{2}=p_{2} \quad a_{2} \cos A_{2}=q_{2} \\
& \begin{array}{ccc}
\cdots & \cdots & \cdots
\end{array} \\
& \begin{array}{cccc}
\ldots & \ldots & \ldots
\end{array}
\end{aligned}
$$

$f(t)=a_{o}+q_{1} \operatorname{sen} \theta t+p_{1} \cos \theta t+q_{2} \operatorname{sen} 2 \theta t+p_{2} \cos 2 \theta t+$

$$
\ldots+q_{j} \operatorname{sen} j \theta t+p_{j} \cos j \theta t .
$$

Para o j-ésimo harmônico, tem-se:

$p_{j}=a_{j} \operatorname{sen} A_{j}$ e $q_{j}=a_{j} \cos A_{j}$,

e portanto,

$$
\begin{aligned}
& a_{j}^{2}=p_{j}^{2}+q_{j}^{2} \\
& \frac{p_{j}}{q_{j}}=\operatorname{tg} A_{j}
\end{aligned}
$$

ou ainda:

$$
a_{j}=\sqrt{p_{j}^{2}+q_{j}^{2}}
$$

$A_{j}=\operatorname{arctg}\left(\frac{p_{j}}{q_{j}}\right)$.

Sendo Yt a precipitação mensal observada para $t=1$, $2, \ldots, \mathrm{T}$, onde $\mathrm{t}$ representa os meses em que foram realizadas as medidas, e $\mathrm{T}$ é o comprimento do período a ser estudado, o modelo matemático a ser utilizado, oriundo da série trigonométrica de Fourier, conforme a equação (1), toma a forma:

$Y_{t}=a_{0}+\sum_{j=1}^{k} a_{j} \operatorname{sen}\left(j \theta t+A_{j}\right)+\varepsilon_{t}$

onde:

$\mathrm{a}_{0}=$ média geral dos valores de $\mathrm{Y}$;

$\mathrm{k}=$ maior inteiro que não supere $\mathrm{T} / 2$;

$\mathrm{a}_{\mathrm{j}}=$ amplitude do j-ésimo componente harmônico;

$\mathrm{A}_{\mathrm{j}}=$ ângulo fase do j-ésimo componente harmônico;

$\varepsilon_{\mathrm{t}}=$ efeito residual referente à t-ésima observação;

$\theta=$ freqüência angular.

Desenvolvendo o seno da soma em (9) obtém-se:
$Y_{t}=a_{0}+\sum_{j=1}^{k}\left(a_{j} \operatorname{sen} A_{j} \cos j \theta t+a_{j} \cos A_{j} \operatorname{sen} j \theta t\right)+\varepsilon_{t} ;(10)$

fazendo-se em (10),

$p_{j}=a_{j} \operatorname{sen} A_{j}$

$\mathrm{q}_{\mathrm{j}}=\mathrm{a}_{\mathrm{j}} \cos \mathrm{A}_{\mathrm{j}}$

$\mathrm{y}_{\mathrm{t}}=\mathrm{Y}_{\mathrm{t}}-\mathrm{a}_{0}$.

Assim, para o caso atual em que T é par, o modelo pode ser representado da seguinte forma:

$\mathrm{y}_{\mathrm{t}}=\sum_{\mathrm{j}=1}^{\mathrm{k}-1} \mathrm{p}_{1} \cos \theta \mathrm{t}+\mathrm{p}_{2} \cos 2 \theta \mathrm{t}+\ldots+\mathrm{p}_{(\mathrm{k}-1)} \cos (\mathrm{k}-1) \theta \mathrm{t}+$

$\mathrm{p}_{\mathrm{k}} \cos \mathrm{k} \theta \mathrm{t}+\mathrm{q}_{1} \operatorname{sen} \theta \mathrm{t}+\mathrm{q}_{2} \operatorname{sen} 2 \theta \mathrm{t}+\ldots+\mathrm{q}_{(\mathrm{k}-1)} \operatorname{sen}(\mathrm{k}-1) \theta \mathrm{t}+$

$\varepsilon_{\mathrm{t} .}$.

Como no caso deste trabalho, em que o período é anual $(\mathrm{T}=12)$, o modelo oriundo de (14) fica:

$\mathrm{y}_{\mathrm{t}}=\mathrm{p}_{1} \cos \theta \mathrm{t}+\mathrm{p}_{2} \cos 2 \theta \mathrm{t}+\mathrm{p}_{3} \cos 3 \theta \mathrm{t}+\mathrm{p}_{4} \cos 4 \theta \mathrm{t}+$ $\mathrm{p}_{5} \cos 5 \theta \mathrm{t}+\mathrm{p}_{6} \cos 6 \theta \mathrm{t}+\mathrm{q}_{1} \operatorname{sen} \theta \mathrm{t}+\mathrm{q}_{2} \operatorname{sen} 2 \theta \mathrm{t}+$ $\mathrm{q}_{3} \operatorname{sen} 3 \theta t+\mathrm{q}_{4} \operatorname{sen} 4 \theta t+\mathrm{q}_{5} \operatorname{sen} 5 \theta t+\varepsilon_{t}$ onde:

$\theta=360 / 12=30^{\circ} \mathrm{e}, \mathrm{t}=1,2 \ldots 12$.

Como em cada mês têm-se $n=31$ repetições, $\mathrm{y}_{\mathrm{ti}}=\mathrm{p}_{1 \mathrm{i}} \cos \theta \mathrm{t}+\mathrm{p}_{2 \mathrm{i}} \cos 2 \theta \mathrm{t}+\mathrm{p}_{3 \mathrm{i}} \cos 3 \theta \mathrm{t}+\mathrm{p}_{4 \mathrm{i}} \cos 4 \theta t+$ $\mathrm{p}_{5 \mathrm{i}} \cos 5 \theta \mathrm{t}+\mathrm{p}_{6 \mathrm{i}} \cos 6 \theta \mathrm{t}+\mathrm{q}_{1 \mathrm{i}} \operatorname{sen} \theta \mathrm{t}+\mathrm{q}_{2 \mathrm{i}} \operatorname{sen} 2 \theta \mathrm{t}+$ $\mathrm{q}_{3 \mathrm{i}} \operatorname{sen} 3 \theta \mathrm{t}+\mathrm{q}_{4 \mathrm{i}} \operatorname{sen} 4 \theta \mathrm{t}+\mathrm{q}_{5 \mathrm{i}} \operatorname{sen} 5 \theta \mathrm{t}+\varepsilon_{\mathrm{ti}}$.

Dessa forma, a matriz $\mathrm{X}$ terá as dimensões $\mathrm{T} \times \mathrm{n}$, ou seja, $12 \times 31$

A solução do sistema de equações resultou numa matriz $\beta$, de dimensões $11 \times 31$, contendo todos os $\mathrm{T}-1=11$ contrastes estimados para cada um dos $\mathrm{N}=31$ anos.

Com o objetivo de obter a equação de regressão referente ao período anual, cada um dos $\mathrm{T}-1=11$ contrastes foi obtido pela média de seus valores estimados durante os $\mathrm{N}=31$ anos.

Com estes valores médios, foram calculadas as estimativas de $\mathrm{a}_{\mathrm{j}}$ e $\mathrm{A}_{\mathrm{j}}$, conforme descrito em (7) e (8).

De modo genérico, de todos os dados resulta um sistema de equações que pode ser representado matricialmente por:

$\mathrm{Y}=\mathrm{X} \beta+\varepsilon$

onde:

$[\mathrm{Y}]=$ vetor das observações $\mathrm{y}_{\mathrm{t}}$;

$[\mathrm{X}]=$ matriz dos coeficientes;

$[\beta]=$ vetor dos parâmetros $\mathrm{p}_{\mathrm{j}}$ e $\mathrm{q}_{\mathrm{j}}$;

$[\varepsilon]=$ vetor dos erros aleatórios.

A estimativa dos parâmetros, bem como as suas variâncias e covariâncias, foi obtida pelo método dos mínimos quadrados, chegando-se à solução do seguinte sistema de equações:

$\beta=S^{-1} X^{\prime} Y$,

onde a matriz $\mathrm{S}$ é não-singular, resultante da multiplicação da transposta da matriz X pela própria matriz X, ob- 
tendo-se, por álgebra matricial, a estimativa dos parâmetros $p_{j}$ e $q_{j}$.

\section{Transformação dos dados}

Inicialmente, os dados foram ajustados considerandose todos os meses com 30 dias, com o objetivo de corrigir as diferenças de sua duração.

Uma das exigências do modelo matemático e dos testes de significância é que os erros aleatórios tenham distribuição normal. Quando isto não ocorre, Amaral (1968) aconselha a realização de uma transformação dos dados baseada na fórmula $\sigma_{x}=\beta x^{a}$, na qual os valores de a e $\beta$ podem ser determinados em cada grupo de observações, sendo $\mathrm{x}$ a média da precipitação mensal de um período de $\mathrm{N}$ anos, e $\sigma_{\mathrm{x}} \mathrm{o}$ desvio-padrão das observações utilizadas para o cálculo desta média. Amaral (1968) propõe uma transformação do tipo $\mathrm{y}=\mathrm{x}^{(1-a)}$, após a determinação do valor de a. Silva (1977), estudando a precipitação pentadal de Pelotas, utilizou a transformação $\mathrm{y}=\mathrm{x}^{0,333}$, estimada pelo método apresentado por Amaral (1968). Pereira (1978) empregou a transformação $y=\log (x+35)$. Feltrin (1980) e Santos (1984) aplicaram as transformações $\mathrm{y}=\mathrm{x}^{0,5}$ e $\mathrm{y}=\mathrm{x}^{0,325}$ a dados de precipitação mensal, respectivamente.

Assim, foi efetuada uma transformação dos dados, cujos valores específicos de cada localidade são citados na Tabela 1. Entre estas transformações se incluem as que foram utilizadas por Silva (1977) e Feltrin (1980), bem como as transformações resultantes da fórmula proposta por Amaral (1968). Entretanto, como estas opções ainda não foram suficientes para a normalização dos erros aleatórios em todos os locais, elaborou-se uma seqüência de potências da variável a ser transformada, constituída de múltiplos e divisores das transformações utilizadas por Silva (1977) e Feltrin (1980), ou seja: 0,1665, 0,250, 0,333, $0,500,0,667,1,000,1,333$ e 1,500. A aplicação desta seqüência a todos os locais permitiu identificar a transformação necessária e suficiente para normalizar os erros aleatórios de cada local. Adotou-se o critério de utilizar a transformação mais próxima da unidade, ou seja, da ausência de transformação. Como não foi objetivo deste trabalho realizar o agrupamento ou a comparação estatística entre locais, não foi necessário identificar uma transformação única para todos os locais.

\section{Teste de normalidade}

Considerando-se que as observações mensais foram repetidas durante $\mathrm{N}$ períodos ou anos, é conveniente utilizar a análise de variância para testar a estabilidade dos componentes harmônicos, no decorrer dos $\mathrm{N}$ períodos estudados.
Entretanto, para que a análise de variância possa ser aplicada aos contrastes, é necessário que seja testada sua normalidade, atendendo a uma das exigências do teste $\mathrm{F}$. Amaral (1968) aconselha que seja utilizado o teste de normalidade para grandes amostras, apresentado por Fisher (1941). Neste teste se comparam as medidas de assimetria $\left(\mathrm{g}_{1}\right)$ e curtose $\left(\mathrm{g}_{2}\right)$ dos contrastes, com as medidas de assimetria $\left(g_{1}=0\right)$ e curtose $\left(g_{2}=0\right)$ da distribuição normal, através do teste $t$, respectivamente.

As estatísticas $g_{1}$ e $g_{2}$ são estimadas pelas fórmulas propostas por Fisher (1941) e aplicadas a dados de precipitação mensal do Brasil por Amaral (1968), Thiebaut (1976), Pereira (1978), Feltrin (1980), Santos (1984) e Queiroz (1988):

$$
\begin{aligned}
& \hat{\mathrm{g}}_{1}=\left[\frac{\left(\mathrm{w}_{3}\right)^{2}}{\left(\mathrm{w}_{2}\right)^{3}}\right]^{0,5} \\
& \hat{\mathrm{g}}_{2}=\frac{\mathrm{w}_{4}}{\mathrm{w}_{2}^{2}}
\end{aligned}
$$

onde, $\mathrm{w}_{2}, \mathrm{w}_{3}$ e $\mathrm{w}_{4}$ são o segundo, terceiro e quarto momentos, em relação à média.

Nestas fórmulas, para o contraste $\mathrm{p}_{1}$, por exemplo, temse:

$\mathrm{W}_{2}=\frac{\sum_{\mathrm{i}=1}^{\mathrm{N}}\left(\hat{\mathrm{p}}_{1 \mathrm{i}}-\overline{\mathrm{p}}_{1}\right)^{2}}{(\mathrm{~N}-1)}$,

$\mathrm{W}_{3}=\frac{\mathrm{N} \sum_{\mathrm{i}=1}^{\mathrm{N}}\left(\hat{\mathrm{p}}_{\mathrm{li}}-\overline{\mathrm{p}}_{1}\right)^{3}}{(\mathrm{~N}-1)(\mathrm{N}-2)}$,

$\mathrm{W}_{4}=\frac{\mathrm{N}}{(\mathrm{N}-1)(\mathrm{N}-2)(\mathrm{N}-3)} \mathrm{X}\left\{(\mathrm{N}+1) \sum_{\mathrm{i}=1}^{\mathrm{N}}\left(\hat{\mathrm{p}}_{1 \mathrm{i}}-\overline{\mathrm{p}}_{1}\right)^{4}-\right.$

$\left.\frac{3(\mathrm{~N}-1)}{\mathrm{N}}\left[\sum_{\mathrm{i}=1}^{\mathrm{N}}\left(\hat{\mathrm{p}}_{\mathrm{li}}-\overline{\mathrm{p}}_{1}\right)^{2}\right]^{2}\right\}$

Segundo Amaral (1968), g g e g têm distribuição normal de média igual a zero e desvios-padrões dados por:

$$
\begin{aligned}
& s\left(\hat{\mathrm{g}}_{1}\right)=\sqrt{\frac{6 \mathrm{~N}(\mathrm{~N}-1)}{(\mathrm{N}-2)(\mathrm{N}+1)(\mathrm{N}+3)}} \\
& \mathrm{s}\left(\hat{\mathrm{g}}_{2}\right)=\sqrt{\frac{24 \mathrm{~N}(\mathrm{~N}-1)^{2}}{(\mathrm{~N}-3)(\mathrm{N}-2)(\mathrm{N}+3)(\mathrm{N}+5)}}
\end{aligned}
$$


A distribuição de cada contraste é considerada como aproximadamente normal, se, a um determinado nível de significância, os valores de $t$ calculado forem menores que os valores de $\mathrm{t}$ tabelado, com $\mathrm{N}-1$ graus de liberdade, comprovando-se as seguintes hipóteses de nulidade:

$\mathrm{H}_{0}: \mathrm{g}_{1}=0 \quad \mathrm{H}_{0}: \mathrm{g}_{2}=0$

$\mathrm{H}_{1}: \mathrm{g}_{1} \neq 0 \quad \mathrm{H}_{1}: \mathrm{g}_{2} \neq 0$.

Os valores de $\mathrm{t}$ calculado, para testar os coeficientes de assimetria e curtose, são dados pelas equações (24) e (25), respectivamente.

$\mathrm{t}_{1}=\frac{\hat{\mathrm{g}}_{1}}{\mathrm{~s}\left(\hat{\mathrm{g}}_{1}\right)}$

$\mathrm{t}_{2}=\frac{\hat{\mathrm{g}}_{2}}{\mathrm{~s}\left(\hat{\mathrm{g}}_{2}\right)}$

Como, no caso específico deste trabalho, as observações foram realizadas durante 31 períodos ou anos, temse que $\mathrm{N}=31$, em todos os locais estudados, e as estimativas dos desvios padrão foram:

$\mathrm{s}\left(\mathrm{g}_{1}\right)=0,421$ e $\mathrm{s}\left(\mathrm{g}_{2}\right)=0,821$

e o valor de $\mathrm{t}$ tabelado para o nível de $95 \%$ de probabilidade e 30 graus de liberdade é 2,04. Assim os valores máximos que podem ser admitidos para os coeficientes de assimetria e curtose para haver normalidade são:

$\mathrm{g}_{1}=\mathrm{s}\left(\mathrm{g}_{1}\right) \mathrm{t}_{1}=0,421 \times 2,04=0,859$,

e,

$\mathrm{g}_{2}=\mathrm{s}\left(\mathrm{g}_{2}\right) \mathrm{t}_{2}=0,821 \times 2,04=1,675$.

Assim, em cada local, após a aplicação deste teste, em cada uma das transformações anteriormente mencionadas, foi escolhida a transformação que, concomitantemente, produziu coeficientes de assimetria e curtose menores do que 0,859 e 1,675 , respectivamente, e eram os mais próximos dos valores calculados com os dados originais, ou seja, na ausência de transformação. De modo idêntico, a comparação dos valores de t calculado com o valor tabelado de 2,04 constituiu outro caminho para a escolha da transformação, utilizando o mesmo critério.

\section{Análise da variação}

Comprovada a normalidade dos contrastes pela utilização da transformação adequada, foi aplicada a análise da variação pelo teste F. Segundo Amaral (1968), a análise da variação também deve ser aplicada a cada amplitude dos componentes harmônicos, por meio da junção dos contrastes que a compõem, desde que as variâncias residuais destes contrastes sejam homogêneas. Após a determinação, por meio da análise da variação dos componentes harmônicos significativos, foi estabelecida a equação de regressão dos dados observados e no nível de significância escolhido. Para tanto, foram considerados todos os componentes harmônicos até o último que seja significativo, para o nível de probabilidade considerado.

Portanto, admitida a hipótese de que as precipitações mensais se distribuam normalmente, em torno das respectivas médias e com a mesma variância $\sigma^{2}$, a distribuição das amplitudes dos componentes harmônicos é dada pela seguinte equação diferencial:

$\mathrm{dP}=\frac{\mathrm{Na}}{2 \sigma^{2}} \mathrm{e}^{-\mathrm{Na}^{2} / 4 \sigma^{2}} \mathrm{da}$

onde, a é a amplitude da onda, $\mathrm{N}$ é o período fundamental (no caso deste trabalho $\mathrm{N}=12$ meses), $\sigma^{2}$ é a variância (Amaral, 1968).

A verdadeira variância $\sigma^{2}$ não é conhecida, porém pode ser estimada com base nas observações de um razoável conjunto de anos e estendida aos anos posteriores, o que implica admitir a estabilidade da variância.

A diferencial:

$\mathrm{dP}=\frac{\mathrm{Na}}{2 \sigma^{2}} \mathrm{e}^{-\mathrm{Na}^{2} / 4 \sigma^{2}}$ da, $\quad 0 \leq \mathrm{a}<+\infty$

é, a menos de um infinitésimo de ordem superior à primeira em relação à da, a probabilidade de que a amplitude de uma onda casual esteja compreendida entre a e a $+\mathbf{d a}$.

Adotando-se o nível de significância de 5\% de probabilidade $(\alpha=0,05)$, o valor de a acima do qual a amplitude de uma onda, com dois graus de liberdade, será significante, é dado pela integral:

$\int_{0}^{\mathrm{a}} \frac{\mathrm{Na}}{2 \sigma^{2}} \mathrm{e}^{-\mathrm{Na}^{2} / 4 \sigma^{2}} \mathrm{da}=1-\alpha=0,95$

Integrando, tem-se:

$\left[-\mathrm{e}^{-\mathrm{Na}^{2} / 4 \sigma^{2}}\right]_{0}^{\mathrm{a}}=1-\mathrm{e}^{\mathrm{Na}^{2} / 4 \sigma^{2}}$

donde:

$\alpha=\mathrm{e}^{-\mathrm{Na}^{2} / 4 \sigma^{2}}$

$a=2 \sigma \sqrt{\frac{-\log \alpha}{N}}$

Assim, se $\mathrm{a}=0,05=1 / 20$,

$a=2 \sigma \sqrt{\frac{\log 20}{N}}$

onde,

$\log 20=(\log 20) / 0,4343$.

Fazendo em (32),

$\lambda=2 \sqrt{\log 20}$ 
fica,

$\mathrm{a}=\lambda \sigma / \sqrt{\mathrm{N}}$.

\section{Probabilidade de ocorrência de ano conforme o modelo}

A partir da equação (31), fixando-se o nível de probabilidade $(\alpha)$, calculou-se o valor acima do qual a amplitude é significativa. Por outro lado, conhecendo-se o valor de determinada amplitude é possível determinar o nível de probabilidade de ocorrência de determinado modelo, desde que esta amplitude corresponda à onda harmônica de maior ordem, que o integra.

Desse modo, a equação (31) ficcou:

$\mathrm{a}^{2}=4 \sigma^{2}(-\ln \alpha / \mathrm{N}), \mathrm{e}$,

$-\ln \alpha=\mathrm{Na}^{2} / 4 \sigma^{2}$.

Como, para o caso atual, $\mathrm{N}=12$, fica:

$-\ln \alpha=12 \mathrm{a}^{2} / 4 \sigma^{2}=3 \mathrm{a}^{2} / \sigma^{2}$.

Tomando-se a exponencial: $\alpha=\mathrm{e}^{-\left(3 \mathrm{a}^{2} / \sigma^{2}\right)}$

Finalmente, a probabilidade de ocorrência de um ano conforme o modelo escolhido, fica:

$\mathrm{P}=1-\alpha$,

que pode ser expressa em porcentagem.

De modo análogo, foi estimada a probabilidade de ocorrência de um ano médio escolhendo a menor amplitude entre todos os seis termos e, portanto, da equação que reproduz a média, conforme propriedade da série de Fourier.

A variância $\sigma^{2}$ da equação (32) foi estimada conforme proposto por Brunt, citado por Amaral (1968), utilizando a equação (35), para o ano, conforme a média,

$\sigma_{\mathrm{t}}^{2}=\frac{1}{2}\left(\mathrm{a}_{1}^{2}+\mathrm{a}_{2}^{2}+\mathrm{a}_{3}^{2}+\mathrm{a}_{4}^{2}+\mathrm{a}_{5}^{2}\right)+\mathrm{a}_{6}^{2}$

e a equação (36), para o ano, conforme o modelo, com o número de termos igual ao do modelo

$\sigma_{\mathrm{m}}^{2}=\frac{1}{2}\left(\mathrm{a}_{1}^{2}+\mathrm{a}_{2}^{2}+\mathrm{a}_{3}^{2}+\ldots+\mathrm{a}_{\mathrm{n}}^{2}\right)$.

\section{Resultados e Discussão}

$\mathrm{Na}$ agricultura, as épocas de realização de diversas operações agrícolas, principalmente as épocas de plantio, colheita, aplicação de irrigação e algumas outras práticas culturais, são planejadas em função das disponibilidades hídricas. Por outro lado, o conhecimento do regime de chuvas de um local ou área permite que se instale a cultura de modo que haja o máximo aproveitamento das disponibilidades hídricas através do atendimento das exigências da referida cultura.
A utilização da precipitação mensal em estudos das disponibilidades hídricas, para aplicações na agricultura, tem sido criticada pelo fato de que esta variável não consegue detectar algumas variações de curto prazo, que são relevantes para o comportamento das culturas e influenciam diversas operações agrícolas. Esta insuficiência é resultante da distribuição da precipitação diária ao longo do tempo, combinada com a sensibilidade de atividades operacionais e subperíodos fenológicos críticos, menores do que um mês, à ocorrência de deficiência hídrica.

Uma das estimativas mais precisas das disponibilidades hídricas, para o atendimento às exigências hídricas das culturas, baseia-se na execução do balanço hídrico seriado diário, apresentado por Baier \& Robertson (1966), utilizando a equação proposta por Penman (1956) para o cálculo da evapotranspiração. Este método permite estimar a disponibilidade hídrica para a capacidade de armazenamento de água do solo no qual está instalada determinada cultura. As variáveis utilizadas para a execução deste balanço hídrico são temperatura média do ar, precipitação, velocidade do vento a $2 \mathrm{~m}$ de altura do solo e radiação solar, e devem ser coletadas diariamente.

Berlato (1987) aplicou o método apresentado por Baier \& Robertson (1966), utilizando a equação de Penman (1956) para o cálculo da evapotranspiração diária, em diversas localidades do Rio Grande do Sul, nas quais foram conduzidos experimentos ecológicos por vários anos, e derivou um modelo matemático de relação entre o consumo de água e rendimento de soja. Queiroz et al. (1996) também aplicou este método para estimar a evapotranspiração diária da soja, em Londrina, Paraná, com base nos dados de um experimento ecológico, conduzido por oito anos consecutivos, e derivou um modelo matemático de quantificação do efeito da oferta hídrica sobre a resposta da soja à época de plantio.

Entretanto, nem sempre estão disponíveis todas as informações sobre estas variáveis meteorológicas primárias de um número de anos suficientemente grande para permitir que se estime, pelo procedimento proposto por Penman (1956), a disponibilidade hídrica para uma região ou Estado. Ademais, a generalização dos resultados exige a condução dos experimentos ecológicos com o mesmo nível de preci- 
são, em outras localidades da região de estudo, o que apresenta uma alta exigência de recursos financeiros e humanos, nem sempre disponíveis.

Nestas circunstâncias, Queiroz (1988) determinou a região para a qual os seus resultados podem ser generalizados utilizando informações do Levantamento de Solos e das Cartas Climáticas Básicas do Estado do Paraná, elaboradas a partir de informações de precipitação mensal de diversas localidades daquele Estado. A generalização dos resultados de Berlato (1987) também poderá ser feita através de procedimentos análogos, os quais são adotados com grande freqüência, em situações similares no Brasil e no exterior.

Ademais, a precipitação mensal estando disponível para maior número de anos e locais, tem sido largamente utilizada, principalmente, quando se deseja detectar médias climatológicas e anomalias referentes a eventos de grande escala geográfica, intensidade e persistência (Godoy et al., 1978; Casarin 1982; Kousky \& Cavalcanti, 1984; Kayano \& Moura, 1986; Corrêa et al., 1994).

Assim, a precipitação mensal é um valioso instrumento de estudo das disponibilidades hídricas, sua variabilidade e probabilidades de ocorrência, especialmente quando voltado para os eventos e anomalias de grande escala ou utilizado para a generalização de trabalhos detalhados que não podem ser repetidos em grande número de locais e anos.

\section{Transformação dos dados}

O efeito das transformações aplicadas aos dados das oito séries históricas analisadas neste trabalho, sobre os coeficientes de assimetria e curtose de alguns contrastes, estão apresentados na Tabela 2. Estes resultados são referentes apenas aos contrastes cujas distribuições mais se afastaram da distribuição normal, os quais apresentaram os mais altos valores de $\mathrm{t}$ calculado, e que, em última análise, foram os que determinaram a necessidade da utilização da transformação escolhida.

Conforme apresentado em Material e Métodos, os valores de $t$ calculado, referentes aos coeficientes de assimetria e curtose, para determinada transformação, que foram, concomitantemente, inferiores a 2,04 , indicam que a distribuição do contraste correspondente segue a distribuição normal. No caso da
Tabela 2, a ocorrência, concomitante, de valores dos coeficientes de assimetria e curtose inferiores, respectivamente, a 0,859 e 1,675, para determinada transformação, indica que o contraste apresenta distribuição normal.

Os dados das localidades de Morretes, Adrianópolis e Cerro Azul (Balsa) não foram submetidos à transformação, pois os seus contrastes apresentaram distribuição normal, na ausência de transformação (Tabela 2).

As transformações resultantes da aplicação do procedimento sugerido por Amaral (1968), bem como a transformação utilizada por Feltrin (1980), somente não foram capazes de normalizar a distribuição dos contrastes referentes às localidades de Paranaguá, Morretes (Véu da Noiva) e Campina Grande do Sul. Os dados das localidades de Paranaguá e Campina Grande do Sul, respectivamente, exigiram as transformações $\mathrm{y}=\mathrm{x}^{1,333}$ e $\mathrm{y}=\mathrm{x}^{0,1665}$, para que as distribuições dos seus diversos contrastes fossem normalizadas. A transformação $\mathrm{y}=\mathrm{x}^{0,333}$, utilizada por Silva (1977), foi a que normalizou a distribuição dos contrastes da localidade de Morretes - Véu da Noiva (Tabela 2).

$\mathrm{Na}$ localidade de Campina Grande do Sul o contraste $\mathrm{p}_{4}$ foi o mais rebelde, ou seja, o que mais resistiu ao procedimento adotado para a normalização da distribuição, o que foi indicado principalmente pelo coeficiente de assimetria.

Este resultado pode ser oriundo de, pelo menos, três causas, atuando isoladamente ou em conjunto.

No sentido físico, ou seja, do ponto de vista meteorológico, o desvio da distribuição normal pode ter sido causado pela ocorrência de anomalias da precipitação na localidade de Campina Grande do Sul, com intensidade suficiente para exigirem este nível de transformação para a normalização da distribuição dos contrastes. Uma evidência desta possibilidade é ocorrência de conhecidas anomalias da precipitação nos anos em que alguns contrastes exigiram a transformação. Observando-se os coeficientes de assimetria e curtose relativos ao contraste $\mathrm{p}_{4}$, em cada um dos anos estudados na localidade de Campina Grande do Sul, constatou-se que a exigência de transformação foi oriunda principalmente dos anos 1964, 1983 e 1970. Os anos de 1964 e 1970 podem ser considerados anômalos, tendo em vista que as ob- 
servações de precipitação mensal apresentadas por Bizzoni \& Romagna (1984) em diversas localidades do Estado do Paraná, situam-se bem abaixo das médias destas localidades, apesar de que não tenha sido localizada a informação sobre as causas da seca observada nestes anos. Uma das limitações deste entendimento é o fato de que as outras localidades próximas e estudadas neste trabalho, as quais estiveram expostas à mesma anomalia, não exigiram transformações tão radicais para que a distribuição de seus contrastes fosse normalizada. A assimetria referente ao ano de 1983 pode ser atribuída à ocorrência de um evento de El Niño, que, conforme observações e conclusões de Kousky \& Cavalcanti (1984) e Kayano \& Moura (1986), provocou uma anomalia positiva da precipitação em diversos locais do Estado do Paraná. Não foi observado um comportamento suficientemente consistente dos coeficientes de assimetria e curtose, que permitisse associá-lo à anomalia, ocorrida nos anos de 1978 e 1979, e descrita por Casarin (1982) como resultante de sistemas de bloqueio na circulação do hemisfério sul, com impacto sobre o sul do Brasil.
No que se refere ao método utilizado, pode-se pensar que este trabalho, analisando oito locais, esteve exposto a uma diversidade de regimes hídricos associada a uma variabilidade que não ocorreu no caso dos trabalhos realizados por Silva (1977) e Feltrin (1980), que analisaram um local, e por Amaral (1968), que analisou dois locais. Foi afastada a hipótese de que a dificuldade da normalização dos contrastes fosse oriunda do fato de que, neste trabalho, foram utilizados 31 anos de observação, enquanto nos trabalhos de Feltrin (1980) e Amaral (1968) foram utilizados 48 e 52 anos, respectivamente. Admitiu-se que o período de 30 anos, sendo utilizado, normalmente, nos estudos climatológicos, proporciona uma amostra de tamanho suficiente para a aplicação dos testes de normalidade propostos por Fisher (1941). Em conseqüência, considerou-se que é lícito utilizar as transformações $\mathrm{y}=\mathrm{x}^{0,1665}$ e $\mathrm{y}=\mathrm{x}^{1,333}$, que vêm sendo estudadas por Hoaglin et al. (1992) e que foram aplicadas aos dados das localidades de Campina Grande do Sul e Paranaguá, respectivamente.

Finalmente, a causa do problema pode ser oriunda da qualidade da série histórica estudada, compro-

Tabela 2. Efeito de transformações sobre os valores dos coeficientes de assimetria e curtose, de alguns contrastes, para a precipitação mensal de oito localidades das zonas hidrográficas do litoral e da vertente atlântica, no Estado do Paraná (1960-90).

\begin{tabular}{|c|c|c|c|c|c|c|c|}
\hline \multirow[t]{2}{*}{ Localidade } & \multirow[t]{2}{*}{ Contraste } & \multirow[t]{2}{*}{$\begin{array}{l}\text { Identificação do } \\
\text { coeficiente }^{(1)}\end{array}$} & \multicolumn{3}{|c|}{$\begin{array}{l}\text { Coeficientes dos contrastes originais } \\
\text { e transformados }\end{array}$} & \multicolumn{2}{|c|}{$\begin{array}{c}\text { Transformações } \\
\text { usadas }\end{array}$} \\
\hline & & & Original & Amaral & Escolhido & Amaral & Escolhida \\
\hline \multirow[t]{2}{*}{ Antonina } & \multirow[t]{2}{*}{$\mathrm{p}_{5}$} & Assimetria & 0,930 & 0,688 & 0,735 & 0,619 & 0,667 \\
\hline & & Curtose & 1,773 & 0,939 & 1,075 & & \\
\hline \multirow[t]{2}{*}{ Paranaguá } & \multirow{2}{*}{$\mathrm{q}_{3}$} & Assimetria & 0,807 & 1,309 & 0,533 & 0,343 & 1,333 \\
\hline & & Curtose & 1,896 & 3,307 & 1,363 & & \\
\hline \multirow{2}{*}{ Morretes (1) } & \multirow{2}{*}{$\mathrm{p}_{5}$} & Assimetria & $-0,112$ & $-0,204$ & $-0,112$ & 0,659 & 1,000 \\
\hline & & Curtose & 1,504 & 0,809 & 1,504 & & \\
\hline \multirow[t]{2}{*}{ Morretes (2) } & \multirow[t]{2}{*}{$\mathrm{p}_{4}$} & Assimetria & $-0,491$ & $-0,529$ & $-0,481$ & 0,562 & 0,333 \\
\hline & & Curtose & 2,363 & 1,947 & 1,556 & & \\
\hline \multirow[t]{2}{*}{ Campina G. do Sul } & \multirow[t]{2}{*}{$\mathrm{p}_{4}$} & Assimetria & 1,439 & 1,151 & 0,755 & 0,507 & 0,1665 \\
\hline & & Curtose & 2,436 & 1,359 & 0,316 & & \\
\hline \multirow[t]{2}{*}{ Adrianópolis } & \multirow[t]{2}{*}{$\mathrm{p}_{1}$} & Assimetria & 0,156 & 0,809 & 0,156 & 0,524 & 1,000 \\
\hline & & Curtose & 1,317 & 0,942 & 1,317 & & \\
\hline \multirow[t]{2}{*}{ Cerro Azul (1) } & \multirow[t]{2}{*}{$\mathrm{q}_{2}$} & Assimetria & 1,006 & 0,670 & 0,854 & 0,490 & 0,667 \\
\hline & & Curtose & 1,907 & 0,493 & 1,143 & & \\
\hline \multirow[t]{2}{*}{ Cerro Azul (2) } & \multirow[t]{2}{*}{$\mathrm{q}_{2}$} & Assimetria & 0,666 & 0,404 & 0,666 & 0,618 & 1,000 \\
\hline & & Curtose & 0,721 & 0,203 & 0,721 & & \\
\hline
\end{tabular}

${ }^{(1)}$ Coeficiente de assimetria máximo para a normalidade: 0,859; coeficiente de curtose máximo para a normalidade: 1,675. 
metendo a sua utilização. Uma certeza neste sentido somente ocorrerá pela localização definitiva do procedimento de transformação dos dados que seja capaz de normalizar a distribuição dos contrastes de um grande conjunto de localidades que contenha grande variabilidade dentro e entre localidades. Neste caso, o procedimento poderá, inclusive, ser utilizado como mais um método de aferição da qualidade das séries históricas e de sua seleção para integrar estudos e trabalhos de pesquisa em Climatologia . Não sendo objetivo deste trabalho desenvolver este método, considerou-se que a qualidade dos dados é suficiente, e utilizou-se, paliativamente, a seqüência de transformações $0,1665,0,250,0,333,0,500,0,667$, $1,000,1,333$ e 1,500 .

\section{Análise da variação}

Os valores e a significância do teste $\mathrm{F}$ para os contrastes $p_{j}$ e $q_{j}$ e das amplitudes $\hat{a}_{j}$ estão apresentados nas Tabelas 3 e 4, para as oito localidades estudadas. Conforme proposto por Amaral (1968) a significância destas amplitudes é o critério a ser utilizado para a escolha dos termos que farão parte da equação de regressão.

Nas localidades de Antonina e Paranaguá, foram significativos os contrastes $\mathrm{p}_{1}, \mathrm{q}_{1}, \mathrm{p}_{2}, \mathrm{q}_{2}$ e $\mathrm{p}_{3}$. Em Antonina, também foi significativo o contraste $p_{4}$. Em Morretes foram significativos os contrastes $\mathrm{p}_{1}$, $\mathrm{q}_{1}, \mathrm{q}_{2}$ e $\mathrm{p}_{3}$. Na localidade de Morretes - Véu da Noi$\mathrm{va}$, foram significativos os contrastes $\mathrm{p}_{1}, \mathrm{q}_{1}, \mathrm{p}_{2}, \mathrm{q}_{2}$, $\mathrm{p}_{4}$ e $\mathrm{q}_{4}$. Na localidade de Morretes - Véu da Noiva, foram significativos os contrastes $\mathrm{p}_{1}, \mathrm{q}_{1}, \mathrm{p}_{2}, \mathrm{q}_{2}, \mathrm{p}_{4} \mathrm{e}$ $\mathrm{q}_{4}$. Em Adrianópolis e Cerro Azul - Balsa foram significativos os contrastes $\mathrm{p}_{1}, \mathrm{q}_{1}, \mathrm{p}_{3}$ e $\mathrm{q}_{3}$. Em Cerro Azul - Turvo, foram significativos os contrastes $p_{1}$, $\mathrm{p}_{2}$ e $\mathrm{p}_{3}$. Finalmente, em Campina Grande do Sul, foram significativos os contrastes $\mathrm{p}_{1}, \mathrm{q}_{1}, \mathrm{p}_{3}$ e $\mathrm{p}_{4}$ (Tabela 3 ).

As amplitudes correspondentes às três primeiras ondas harmônicas foram significativas em Antonina, Paranaguá, Morretes e Adrianópolis. Nas localidades de Cerro Azul - Balsa e Cerro Azul - Turvo, foram significativas as amplitudes correspondentes à primeira e terceira ondas harmônicas. Em Morretes Véu da Noiva, foram significativas as amplitudes correspondentes à primeira, segunda e quarta ondas harmônicas. Em Campina Grande do Sul, foram significativas as amplitudes correspondentes à primeira, terceira e quarta ondas harmônicas. A quinta e a sexta ondas harmônicas não foram significativas em nenhuma das localidades estudadas (Tabela 4).

Após a análise da variação e a aplicação do teste $\mathrm{F}$ para contrastes, foram obtidas as estimativas dos valores das amplitudes $\left(a_{j}\right)$, dos ângulos fase $\left(A_{j}\right)$ e suas respectivas significâncias, com as quais foram escritas as equações que representam o transcurso anual significativo da precipitação mensal e que são apresentadas na Tabela 5, nas oito localidades estudadas, respectivamente. Adotou-se o critério, proposto por Amaral (1968), de incluir nas equações todos os harmônicos até o último que seja significativo.

Tabela 3. Valores e significância do teste $\mathrm{F}$ para os contrastes pj e qj, referentes ao período anual e à precipitação mensal de oito localidades das zonas hidrográficas do litoral e da vertente atlântica, no Estado do Paraná (1960-90).

\begin{tabular}{|c|c|c|c|c|c|c|c|c|c|}
\hline \multirow{2}{*}{$\begin{array}{l}\text { Causas de } \\
\text { variação }\end{array}$} & \multirow[t]{2}{*}{ GL } & \multicolumn{4}{|c|}{ Litoral } & \multicolumn{4}{|c|}{ Vertente atlântica } \\
\hline & & Antonina & Paranaguá & Morretes & $\begin{array}{c}\text { Morretes-Véu } \\
\text { da Noiva }\end{array}$ & $\begin{array}{l}\text { C. Grande } \\
\text { do Sul }\end{array}$ & Adrianópolis & $\begin{array}{l}\text { Cerro Azul } \\
\text { (Balsa) }\end{array}$ & $\begin{array}{c}\text { Cerro Azul } \\
\text { (Turvo) }\end{array}$ \\
\hline Contraste p1 & 1 & $202,028^{* *}$ & $62,870 * *$ & $103,447 * *$ & $72,541 * *$ & $64,043 * *$ & $29,436^{* *}$ & $36,987 * *$ & $48,630^{* *}$ \\
\hline Contraste q1 & 1 & $102,177 * *$ & $143,174 * *$ & $100,761 * *$ & $4,470 *$ & $14,616^{* *}$ & $7,584^{*}$ & $6,267 *$ & 4,021 \\
\hline Contraste $\mathrm{p} 2$ & 1 & $7,839 * *$ & $8,625 * *$ & 3,454 & $18,956^{* *}$ & 0,792 & 3,690 & 1,655 & $4,216^{*}$ \\
\hline Contraste $\mathrm{q} 2$ & 1 & $12,598 * *$ & $9,825 * *$ & $13,644 * *$ & $4,749 *$ & 2,192 & 3,404 & 0,404 & 0,824 \\
\hline Contraste p3 & 1 & $10,963 * *$ & $14,155^{* *}$ & $19,129 * *$ & 2,600 & $8,933 * *$ & $5,281^{*}$ & $4,371 *$ & $4,435 *$ \\
\hline Contraste q3 & 1 & 0,209 & 0,033 & 1,559 & 0,607 & 0,597 & $4,778^{*}$ & $4,934 *$ & 3,448 \\
\hline Contraste p4 & 1 & $5,705^{*}$ & 0,185 & 0,228 & $6,948^{*}$ & $7,028^{*}$ & 1,200 & 2,639 & 2,307 \\
\hline Contraste q4 & 1 & 0,0007 & 0,161 & 0,300 & $8,218 * *$ & 0,327 & 1,434 & 0,003 & 1,633 \\
\hline Contraste p5 & 1 & 0,0007 & 0,328 & 0,191 & 0,152 & 0,064 & 0,0001 & 0,507 & 0,985 \\
\hline Contraste q5 & 1 & 0,524 & 0,119 & 0,001 & 0,400 & 0,491 & 0,388 & 0,283 & 0,981 \\
\hline Contraste p6 & 1 & 1,591 & 1,389 & 0,514 & 0,096 & 0,750 & 1,236 & 0,008 & 0,007 \\
\hline
\end{tabular}

* e**Significativo a $5 \%$ e a $1 \%$ de probabilidade, respectivamente, pelo teste $\mathrm{F}$. 
A porcentagem da variação total explicada por cada onda harmônica e pelos modelos selecionados pelos procedimentos utilizados neste trabalho, está apresentada na Tabela 6. Estes modelos explicaram, respectivamente, de $89,56 \%$ a $99,60 \%$ da variação total devida a meses.

A primeira onda harmônica (onda anual) explicou a maior parte da variação total $(71,06 \%$ a $91,09 \%$ ), sendo significativa em todas as localidades estudadas. A segunda onda harmônica (onda se- mestral) explica de $2,59 \%$ a $8,67 \%$ da variação total, havendo significância para ela em todas as localidades do Litoral (Antonina, Paranaguá, Morretes e Morretes - Véu da Noiva) e para Adrianópolis, localidade da vertente atlântica. O segundo harmônico explicou mais do que o terceiro nas localidades de Antonina, Paranaguá, Morretes e Morretes - Véu da Noiva. O terceiro harmônico (onda quadrimestral) somente não foi significativo em Morretes - Véu da Noiva, tendo os valores referentes a sua porcenta-

Tabela 4. Valores e significância do teste F, referentes às amplitudes da precipitação mensal de oito localidades das zonas hidrográficas do litoral e da vertente atlântica, no Estado do Paraná (1960-90).

\begin{tabular}{|c|c|c|c|c|c|c|c|}
\hline \multirow[t]{2}{*}{ Localidade } & \multicolumn{6}{|c|}{ Amplitude } & \multirow[t]{2}{*}{ Ano } \\
\hline & $a_{1}$ & $a_{2}$ & $a_{3}$ & $\mathrm{a}_{4}$ & $a_{5}$ & $a_{6}$ & \\
\hline Antonina & $152,780 * *$ & $10,143 * *$ & $4,297 *$ & 2,935 & 0,335 & 1,591 & 1,188 \\
\hline Paranaguá & $89,141 * *$ & $9,389 * *$ & $3,965^{*}$ & 0,173 & 0,201 & 1,389 & 1,312 \\
\hline Morretes (1) & $102,462 * *$ & $9,815 * *$ & $7,628 * *$ & 0,270 & 0,111 & 0,514 & $1,655^{* *}$ \\
\hline Morretes (2) & $52,851 * *$ & $10,474 * *$ & 1,510 & $7,547 * *$ & 0,294 & 0,096 & $2,387 * *$ \\
\hline Campina G. do Sul & $39,537 * *$ & 1,435 & $5,286 * *$ & $3,690 *$ & 0,289 & 0,750 & $2,231 * *$ \\
\hline Adrianópolis & $19,251 * *$ & $3,555 *$ & $4,932 *$ & 1,285 & 0,151 & 1,236 & $4,899 * *$ \\
\hline Cerro Azul - Turvo & $29,279 * *$ & 2,329 & $3,832 *$ & 1,918 & 0,983 & 0,007 & $3,411 * *$ \\
\hline Cerro Azul - Balsa & $24,676 * *$ & 1,026 & $4,688^{*}$ & 1,453 & 0,400 & 0,008 & $2,554 * *$ \\
\hline
\end{tabular}

$* \mathrm{e} * *$ Significativo a $5 \%$ e a $1 \%$ de probabilidade, respectivamente, pelo teste $\mathrm{F}$.

Tabela 5. Equações de regressão periódica da precipitação mensal, contendo as ondas harmônicas com amplitudes significativas a $\mathbf{5 \%}$ de probabilidade pelo teste $\mathrm{F}$, de oito localidades das zonas hidrográficas do litoral e da vertente atlântica, no Estado do Paraná (1960-90).

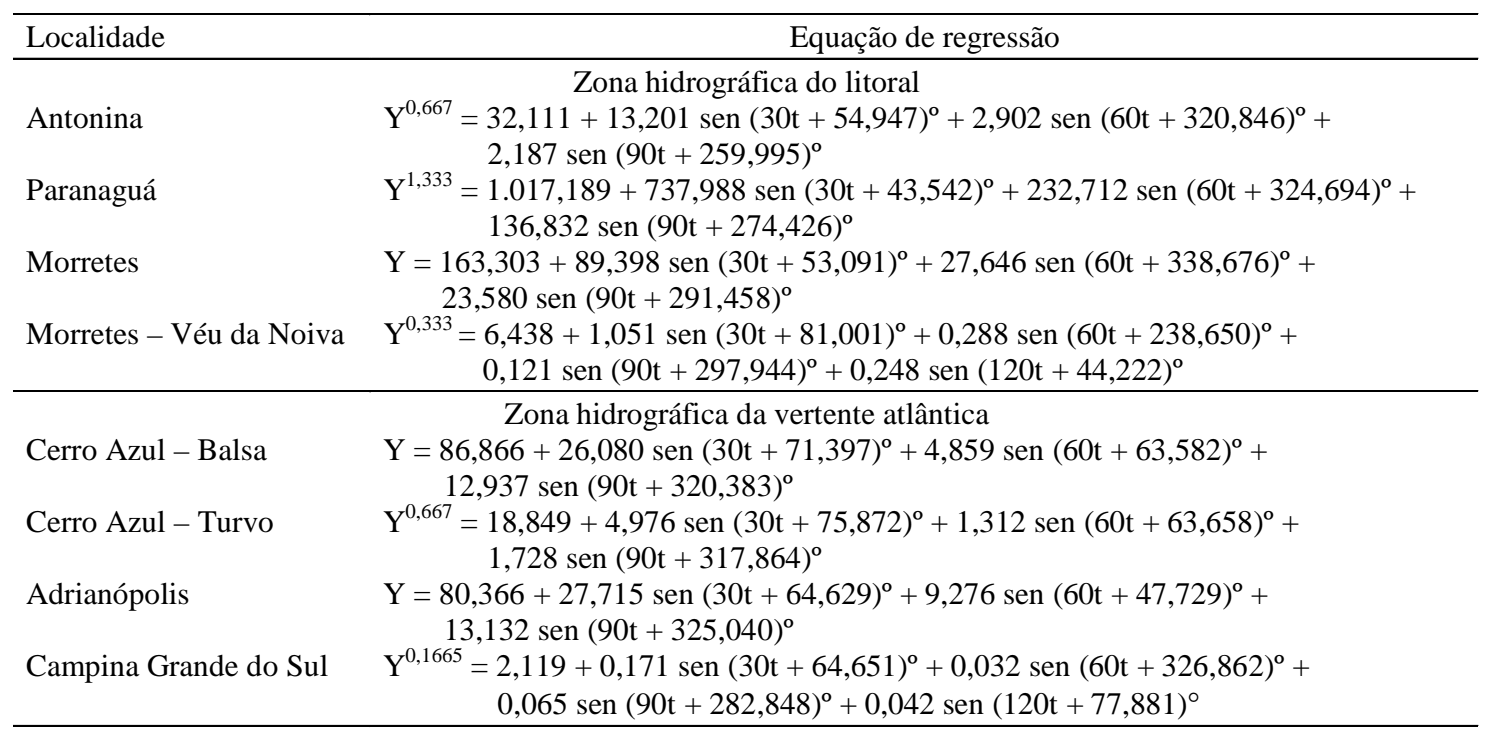


gem da variação total oscilado entre $1,16 \%$ e $18,39 \%$. Nas localidades de Campina Grande do Sul, Adrianópolis e Cerro Azul - Balsa, o terceiro harmônico explica mais do que o segundo. O quarto harmônico (onda trimestral) somente foi significativo em Morretes - Véu da Noiva e Campina Grande do Sul onde explicou, respectivamente, $4,86 \%$ e $4,93 \%$ da variação total. O segundo harmônico não foi significativo em Campina Grande do Sul, Cerro Azul Turvo e Cerro Azul - Balsa. Assim, na maioria dos casos, os três primeiros harmônicos é que integrarão as equações de regressão periódica e, efetivamente, serão os termos responsáveis pela geração dos valores significativos do transcurso anual da precipitação mensal (Tabela 6).

Em nenhuma das localidades estudadas o quinto (onda de 72 dias) e sexto harmônicos (onda bimestral) foram significativos, tendo explicado, respectivamente, de $0,06 \%$ a $1,66 \%$ e de $0,01 \%$ a $1,22 \%$ da variação total. São estes dois harmônicos que, não sendo significativos, não entram no modelo mas entram na composição da média. Portanto, é destes dois termos do modelo que provém a diferença entre os valores resultantes da média e do modelo. Sua exclusão torna mais realista a caracterização do regime hídrico destas localidades, e produz um resultado mais preciso e mais informativo do que a média (Tabela 6).

$\mathrm{Na}$ Tabela 7 estão apresentados os valores das probabilidades de ocorrência de um ano conforme o modelo e conforme a média, calculados segundo o procedimento apresentado em Material e Métodos, bem como os valores das amplitudes utilizadas. Assim, por exemplo, na localidade de Adrianópolis, dados os valores de $\mathrm{a}=13,132$ e $\sigma^{2}=513,307$, obtém-se que a probabilidade de ocorrência de um ano, conforme o modelo, é de $63,50 \%$. Por outro lado, dados os valores de $\mathrm{a}=1,843$ e $\sigma^{2}=540,455$, obtém-se uma probabilidade de $1,87 \%$ para a ocorrência de um ano conforme a média. Observa-se que, nas oito localidades, os valores referentes ao modelo variaram de $14,19 \%$ a $68,42 \%$, enquanto os valores referentes à probabilidade de ocorrência de um ano conforme a média, oscilam de $0,02 \%$ a $1,87 \%$. Em primeiro lugar, estes resultados mostram a baixa probabilidade de ocorrência de um ano conforme a média e maior probabilidade de um ano conforme o modelo. Em segundo lugar, fica evidenciada a existência de grandes diferenças entre locais, no que se refere a estas probabilidades. Finalmente, torna-se claro que é mais eficiente e objetivo usar os valores gerados pelos modelos escolhidos, os quais são mais realistas que os valores resultantes do cálculo da média. Com efeito, os valores gerados pelos modelos apresentam, em todos os locais, maior probabilidade de ocorrência do que os valores resultantes da média.

Estes resultados demonstram que a utilização das equações de regressão periódica, resultantes da marcha de cálculo e do procedimento proposto por Amaral (1968), produz informações superiores às que

Tabela 6. Porcentagem da variação total explicada por cada onda harmônica e pelos modelos referentes à precipitação mensal, do período anual, de oito localidades das zonas hidrográficas do litoral e da vertente atlântica, no Estado do Paraná (1960-90)

\begin{tabular}{|c|c|c|c|c|c|c|c|}
\hline \multirow[t]{2}{*}{ Localidade } & \multicolumn{6}{|c|}{ Onda harmônica } & \multirow[t]{2}{*}{ Modelo } \\
\hline & 1 & 2 & 3 & 4 & 5 & 6 & \\
\hline \multicolumn{8}{|c|}{ Zona hidrográfica do litoral } \\
\hline Antonina & $91,09 * *$ & $4,40 * *$ & $2,50 * *$ & 1,40 & 0,14 & 0,47 & 97,99 \\
\hline Paranaguá & $87,21 * *$ & $8,67 * *$ & $3,00 *$ & 0,15 & 0,18 & 0,80 & 98,88 \\
\hline Morretes & $85,48 * *$ & $8,17 * *$ & $5,95 * *$ & 0,15 & 0,06 & 0,19 & 99,60 \\
\hline Morretes - Véu da Noiva & $87,23 * *$ & $6,55^{* *}$ & 1,16 & $4,86 * *$ & 0,17 & 0,03 & 98,64 \\
\hline \multicolumn{8}{|c|}{ Zona hidrográfica da vertente atlântica } \\
\hline Campina Grande do Sul & $79,88 * *$ & 2,80 & $11,44 * *$ & $4,93 *$ & 0,38 & 0,56 & 96,25 \\
\hline Adrianópolis & $71,06 * *$ & $7,96 *$ & $15,95^{*}$ & 3,49 & 0,31 & 1,22 & 94,97 \\
\hline Cerro Azul - Turvo & $79,92 * *$ & 5,56 & $9,64 *$ & 3,21 & 1,66 & 0,01 & 89,56 \\
\hline Cerro Azul - Balsa & $74,74 * *$ & 2,59 & $18,39^{*}$ & 3,23 & 1,02 & 0,01 & 93,13 \\
\hline
\end{tabular}

$* \mathrm{e} * *$ Significativo a $5 \%$ e a $1 \%$ de probabilidade, respectivamente, pelo teste $\mathrm{F}$. 
são fornecidas pelo cálculo da média aritmética da precipitação mensal. Com efeito, em primeiro lugar, estes resultados foram testados para a significância estatística, para o nível de probabilidade escolhido. Além disso, foi estimada a probabilidade de ocorrência do transcurso anual da precipitação mensal, ou regime hídrico anual significativo, que o modelo é capaz de definir.

\section{Aplicação dos resultados}

Como conseqüência imediata do conhecimento destes resultados, emerge ao espírito de quem necessita tomar decisões referentes aos processos produtivos dependentes do regime hídrico, a expectativa sobre a possibilidade e a viabilidade de sua massificação. A massificação do uso destas informações deverá facilitar a tomada de decisão pelos diversos atores dos processos produtivos que tenham grande dependência do regime de chuvas como é, principalmente, o caso da agricultura. Entretanto, os resultados similares já disponíveis ainda não têm sido utilizados, largamente, para a tomada destas decisões, permanecendo as médias da precipitação mensal ou decendial como principal variável com aplicação prática largamente disseminada. Esta conjuntura gerou a necessidade e determinou a decisão de se trazer, para este trabalho, uma breve discussão sobre a viabilidade da massificação dos procedimentos adotados por Amaral (1968), Thiebaut (1976), Silva (1977), Pereira (1978), Feltrin (1980), Santos (1984) e Queiroz (1988) e aqui utilizados.

$\mathrm{Na}$ época em que Amaral (1968) propôs o uso deste método, sua massificação era impensável em

Tabela 7. Probabilidade de ocorrência, em porcentagem, e amplitudes de ano conforme o modelo escolhido (termos significativos da equação) e conforme a média (todos os termos da equação).

\begin{tabular}{|c|c|c|c|c|c|}
\hline \multirow[t]{2}{*}{ Localidade } & \multicolumn{2}{|c|}{ Amplitude } & \multicolumn{2}{|c|}{ Probabilidade } & \multirow{2}{*}{$\begin{array}{c}\text { Transfor } \\
\text { mação }\end{array}$} \\
\hline & Modelo & Média & Modelo & Média & \\
\hline Antonina & 2,187 & 0,515 & 14,19 & 0,83 & 0,667 \\
\hline Paranaguá & 136,823 & 30,200 & 16,63 & 0,87 & 1,333 \\
\hline Morretes & 23,580 & 2,450 & 30,11 & 0,38 & 1,000 \\
\hline Morretes - V. da Noiva & 0,248 & 0,013 & 25,32 & 0,08 & 0,333 \\
\hline Campina Grande do Sul & 0,042 & 0,010 & 25,32 & 1,63 & 0,1665 \\
\hline Adrianópolis & 13,132 & 1,843 & 63,50 & 1,87 & 1,000 \\
\hline Cerro Azul - Turvo & 1,728 & 0,034 & 45,56 & 0,02 & 0,667 \\
\hline Cerro Azul - Balsa & 12,937 & 0,249 & 68,42 & 0,04 & 1,000 \\
\hline
\end{tabular}

face da pequena capacidade de processamento então disponível. Naquela época, os cálculos deste tipo eram, normalmente, realizados em calculadoras elétricas, já que o computador IBM 1130 somente estava se tornando disponível nos grandes centros avançados de computação. A capacidade de processamento dos atuais microcomputadores é mais do que suficiente para realizar o cálculo aqui proposto para diversas localidades, e a sua disponibilidade estende-se a grande número de pesquisadores e profissionais das diversas áreas do setor produtivo. Esta facilidade estabeleceu a viabilidade de que seja massificado o uso dos modelos aqui propostos, para o cálculo dos valores significativos do transcurso anual da precipitação mensal. Isto possibilita que sejam calculados todos os valores representativos do regime hídrico mensal, principalmente para as localidades que possuam uma série histórica de 30 anos ou mais, melhorando sensivelmente a informação disponível para decisões dos atores dos diversos elos das cadeias produtivas dependentes deste tipo de informação. Tais cálculos podem ser realizados centralizadamente, como é o caso atual das normais climatológicas (Departamento Nacional de Meteorologia, 1992) bem como, diretamente pelos interessados que possuam a série histórica e, no mínimo, um microcomputador da série Pentium ou seus compatíveis e similares.

A Tabela 8 apresenta, para cada um dos doze meses do ano e para cada localidade: 1) a média da precipitação mensal do mesmo período utilizado no cálculo das equações de regressão periódica coincidente com os resultados das equações utilizando todos os seus seis termos; 2) os resultados dos modelos, utilizando apenas os termos significativos.

Estes resultados mostram, em primeiro lugar, que os valores gerados pela utilização de todos os seis termos do modelo coincide com os valores da média aritmética em todas as localidades e meses. Esta coincidência é resultante de propriedade da série de Fourier, pela qual o erro quadrático médio tende para zero à medida que o número de termos tende para $\mathrm{o}$ infinito. Neste caso, o número de termos máximo corresponde à utilização dos seis termos, e o erro quadrático zero corresponde à coincidência entre os valores da média e dos modelos. Secundariamente, esta coincidência demonstra que o programa 
aplicativo desenvolvido para a realização destas análises, apresentado por Thiebaut (1976), foi capaz de realizar os cálculos corretamente e com alta precisão.

As linhas de número dois da Tabela 8 , apresentam os valores do regime hídrico mensal significativo, de cada localidade, que é um dos principais resultados gerados pelos modelos aqui derivados. São estes valores que apresentam maior probabilidade de ocorrência do que a média, a qual, apresentando baixa probabilidade de ocorrência, torna-se bastante teórica, e induz a decisões inadequadas por levar o agricultor a esperar um transcurso da precipitação mensal que, na maioria das vezes, se distancia dos valores reais. Os valores gerados pelo modelo resultam da eliminação dos termos das equações que não tiveram amplitude significativa e explicaram muito pouco da variação total devida a meses.

$\mathrm{Na}$ atividade agrícola, nem sempre é necessário que as informações abranjam um ano completo. Muito freqüentemente a informação sobre uma estação de crescimento (primavera-verão ou outono-inverno) é suficiente. Para estes casos, é mais adequado realizar o cálculo para períodos menores, desde que tenham significado físico. Conforme resultados de Thiebaut (1976), Feltrin (1980) e Queiroz (1988) o cálculo também poderá ser executado para perío- dos inferiores a um ano, tornando a informação mais compatível com a natural subdivisão de culturas e atividades agrícolas em inverno (outono-inverno) e verão (primavera-verão), que, em geral, corresponde a períodos secos ou chuvosos, conforme a região do País. Tal processamento, sem perder informação ou a precisão do método, muito provavelmente resultará em substanciais aumentos de precisão e das probabilidades de ocorrência, pois os períodos serão menores, a freqüência angular será maior, e as equações de regressão periódica terão menor número de termos. Este tipo de informação também pode ser produzido para grande número de localidades, como se faz atualmente, para o cálculo de normais climatológicas de diversas variáveis meteorológicas primárias.

Conforme realizado por Silva (1977) este processamento poderá ser realizado para a precipitação pentadal, e, portanto, também para a precipitação decendial. No caso do uso da precipitação decendial, pode ser detalhado o regime hídrico disponível em subperíodos críticos das culturas menores do que um mês, trazendo informações sobre eventos climatológicos de extensão inferior a um mês, que os modelos baseados nos dados de precipitação mensal não fornecem. Segundo Queiroz et al. (1998), o período de enchimento de grãos é o mais crítico

Tabela 8. Valores de precipitação mensal médios e estimados pelo modelo de regressão periódica para o período 1960-90, de oito localidades das zonas hidrográficas do litoral e da vertente atlântica, no Estado do Paraná.

\begin{tabular}{|c|c|c|c|c|c|c|c|c|c|c|c|c|c|}
\hline Localidade & Valores $^{(1)}$ & Jan. & Fev. & Mar. & Abr. & Maio & Jun. & Jul. & Ago. & Set. & Out. & Nov. & Dez. \\
\hline \multirow[t]{2}{*}{ Antonina } & 1 & 340,1 & 310,4 & 311,9 & 153,9 & 125,4 & 116,8 & 97,3 & 96,6 & 149,8 & 180,9 & 211,8 & 264,9 \\
\hline & 2 & 333,4 & 332,4 & 283,3 & 166,3 & 118,3 & 101,9 & 95,4 & 99,7 & 134,8 & 189,3 & 210,7 & 258,1 \\
\hline \multirow[t]{2}{*}{ Paranaguá } & 1 & 291,0 & 272,3 & 275,0 & 164,7 & 121,8 & 100,2 & 90,3 & 78,1 & 128,9 & 154,1 & 167,2 & 203,5 \\
\hline & 2 & 289,9 & 292,8 & 271,1 & 177,1 & 129,0 & 107,6 & 91,9 & 91,7 & 125,5 & 162,5 & 171,0 & 218,1 \\
\hline \multirow[t]{2}{*}{ Morretes (1) } & 1 & 294,1 & 270,0 & 231,2 & 134,4 & 110,4 & 105,4 & 88,3 & 83,9 & 133,3 & 159,8 & 163,8 & 206,2 \\
\hline & 2 & 287,2 & 277,6 & 225,7 & 134,8 & 113,2 & 103,7 & 86,0 & 89,3 & 128,3 & 162,5 & 162,4 & 209,6 \\
\hline \multirow[t]{2}{*}{ Morretes (2) } & 1 & 429,6 & 330,8 & 375,1 & 256,7 & 205,0 & 183,4 & 164,6 & 182,1 & 321,1 & 416,7 & 362,5 & 429,9 \\
\hline & 2 & 402,8 & 319,2 & 351,1 & 248,4 & 167,6 & 161,3 & 147,3 & 165,6 & 309,2 & 394,8 & 339,8 & 403,8 \\
\hline \multirow[t]{2}{*}{ Campina G. Sul } & 1 & 177,7 & 163,2 & 146,9 & 79,5 & 93,8 & 100,6 & 75,2 & 64,8 & 101,5 & 122,2 & 117,7 & 144,1 \\
\hline & 2 & 155,9 & 150,2 & 129,9 & 67,1 & 61,8 & 74,8 & 54,6 & 51,8 & 90,9 & 108,1 & 96,9 & 129,0 \\
\hline \multirow[t]{2}{*}{ Adrianópolis } & 1 & 136,5 & 96,7 & 86,6 & 58,6 & 73,6 & 71,8 & 55,3 & 46,8 & 77,9 & 84,1 & 79,2 & 110,5 \\
\hline & 2 & 131,8 & 106,1 & 77,1 & 61,8 & 75,9 & 69,7 & 52,5 & 53,7 & 72,4 & 84,0 & 83,4 & 108,2 \\
\hline \multirow[t]{2}{*}{ Cerro Azul T } & 1 & 143,9 & 104,4 & 86,6 & 63,3 & 79,5 & 74,0 & 64,5 & 56,8 & 83,6 & 104,6 & 91,2 & 136,0 \\
\hline & 2 & 136,7 & 106,3 & 76,2 & 59,4 & 70,0 & 66,0 & 53,3 & 54,8 & 74,6 & 94,1 & 97,5 & 118,9 \\
\hline \multirow[t]{2}{*}{ Cerro Azul B } & 1 & 126,4 & 104,9 & 90,7 & 64,3 & 82,5 & 77,9 & 55,6 & 58,3 & 87,6 & 99,9 & 88,3 & 119,7 \\
\hline & 2 & 130,7 & 107,7 & 83,6 & 69,4 & 82,6 & 74,7 & 57,2 & 60,7 & 84,2 & 99,4 & 94,4 & 111,3 \\
\hline
\end{tabular}

(1) 1: média aritmética do período estudado, coincidente com o valor do modelo completo; 2: valores estimados pelo modelo de regressão periódica contendo somente os termos significativos. 
em relação às exigências hídricas da cultura da soja, na região Norte do Paraná. Considerando-se que, para a maioria das lavouras de soja da região, este período ocorre de meados de dezembro a meados de fevereiro, seria muito útil a aplicação dos procedimentos aqui estudados para um período de seis decêndios com início em 20 de dezembro, por exemplo. Neste caso o período será $\mathrm{T}=6$, a freqüência angular será igual a $60^{\circ}$, e o modelo completo terá três termos.

\section{Conclusões}

1. O modelo de análise de regressão periódica é eficiente para a caracterização do transcurso anual da precipitação mensal, das séries históricas das oito localidades estudadas.

2. O modelo explica de $89,56 \%$ a $99,60 \%$ da variação total devida a meses, e a onda anual explica de $71,06 \%$ a 91,09\% dessa variação, nas localidades estudadas.

3. A probabilidade de ocorrência de um ano conforme o modelo (14,19\% a $68,42 \%)$ é muito maior do que a probabilidade de ocorrência de um ano segundo a média $(0,02 \%$ a $1,87 \%)$.

4. Os modelos aqui derivados estimam o transcurso anual da precipitação mensal mais precisamente do que a média aritmética, e contêm mais informação do que esta última.

\section{Agradecimentos}

Aos anônimos revisores gramaticais, pela sua competente e desinteressada contribuição para a clareza e a fidelidade desse texto à Língua Portuguesa.

\section{Referências}

AMARAL, E. Análise harmônica e previsão a longo prazo. In: REUNIÃO INTERNACIONAL DE BIOMETRIA, 1975, Piracicaba. Anais... Piracicaba : Fundação Cargill, 1975. p. 232-271.

AMARAL, E. Análise harmônica. Pesquisa Agropecuária Brasileira, Rio de Janeiro, v. 3, n. 3, p. 7-43, 1968.

BAIER, W.; ROBERTSON, G. W. A new versatile soil moisture budget. Canadian Journal of Plant Science, Ottawa, v. 46, n. 3, p. 299-315, 1966.
BERLATO, M. A. Modelo de relação entre o rendimento de grãos de soja e o déficit hídrico para o Estado do Rio Grande do Sul. São José dos Campos : INPE, 1987. 94 p. Tese de Doutorado.

BIZZONI, O.; ROMAGNA, I. Bacia do Rio Iguaçú. Brasília : Departamento Nacional de Águas e Energia Elétrica, 1984. 79 p. (Boletim Pluviométrico, P-6.1).

BLISS, C. I. Periodic regression in biology and climatology. New Haven : Connecticut Agricultural Experiment Station, 1958. 55 p. (Bulletin, 615).

BROOKS, C. E. P.; CARRUTHERS, N. Handbook of statistical methods in meteorology. London : Meteorological Office, 1953. $412 \mathrm{p}$.

BUDAK, B. M.; FOMIN, S. W. Multiple integrals field theory and series. Moscow: Now, 1973. $650 \mathrm{p}$.

CASARIN, D. P. Um estudo observacional sobre sistemas de bloqueio no Hemisfério Sul. São José dos Campos : INPE, $1982.87 \mathrm{p}$.

CONRAD, V.; POLLAK, L. W. Methods in climatology. Cambridge, Estados Unidos : Harvard University Press, 1950. 459 p.

CORRÊA, A. R.; OLIVEIRA, D.; BORROZINO, E.; GOMES, J.; KIHL, L. R. B.; GRODZKI, L.; CARAMORI, P. H. Cartas climáticas do Estado do Paraná. Londrina : IAPAR, 1994. $45 \mathrm{p}$.

DEPARTAMENTO NACIONAL DE METEOROLOGIA (Brasília, DF). Normais climatológicas (1961-1990). Brasília, 1992. $84 \mathrm{p}$.

FELTRIN, M. A. V. A análise harmônica no estudo das precipitações pluviais no município de Bandeirantes, PR. Piracicaba : ESALQ, 1980. 102 p. Dissertação de Mestrado.

FISHER, R. A. Statistical methods for research workers. 8. ed. London : Oliver and Boyd, 1941. 344 p.

GODOY, M.; CORRÊA, A. R.; BERNARDES, L. R. M. Cartas climáticas básicas do Estado do Paraná. Londrina : IAPAR, 1978. 38 p.

GODOY, M.; CORRÊA, A. R.; SANTOS, O. Clima do Paraná. In: IAPAR (Londrina, PR). Manual agropecuário para o Paraná: 1976. Londrina, 1976. p. 17-87.

HOAGLIN, D. C.; MOSTELLER, F.; TUKEY, J. W. Análise exploratória de dados- técnicas robustas. Lisboa : Salamandra, 1992. $446 \mathrm{p}$. 
KAYANO, M. T.; MOURA, A. D. O El Niño de 1982-83 e a precipitação sobre a América do Sul. Revista Brasileira de Geofísica, São Paulo,v. 4, n. 2, p. 201-214, 1986.

KOUSKY, V. E.; CAVALCANTI, I. F. A. Oscilação do sul - El Niño: características, evolução e anomalias da precipitação. Ciência e Cultura, São Paulo,v. 36, n. 11, p. $1888-1899,1984$

MOTA, F. S. Weather technology models for corn and soybeans in the South of Brazil. Agricultural Meteorology, Amsterdam, v. 28, n. 1, p. 49-64, 1983.

PENMAN, H. L. Evaporation: an introductory survey. Netherlands Journal of Agricultural Science, Wageningen, v. 4, n. 1, p. 9-29, 1956.

PEREIRA, N. S. C. Regressão periódica aplicada a dados pluviométricos mensais do município de Grajaú, MA. Piracicaba : ESALQ, 1978. 66 p. Dissertação de Mestrado

QUEIROZ, E. F. Quantificação do efeito da oferta hídrica sobre a resposta da soja, Glycine max (L.) Merril, à época de plantio na região norte do Paraná. Piracicaba : ESALQ, 1988. 312 p. Tese de Doutorado.
QUEIROZ, E. F.; GAUDÊNCIO, C. A.; GARCIA, A.; TORRES, E.; OLIVEIRA, M. C. N. Efeito de época de plantio sobre o rendimento da soja na região norte do Paraná. Pesquisa Agropecuária Brasileira, Brasília, v. 33, n. 9 , p. 1461-1474, set. 1998 .

QUEIROZ, E. F.; MOLION, L. C. B.; MINOR, H. C.; NEUMAIER, N. Um modelo matemático de quantificação do efeito da disponibilidade hídrica em soja. Pesquisa Agropecuária Brasileira, Brasília, v. 31, n. 10, p. 683690, out. 1996.

SANTOS, W. J. Estudo das precipitações pluviais mensais no município de Bananeiras, $P B$, através de regressão periódica. Piracicaba : ESALQ, 1984. 65 p. Dissertação de Mestrado.

SILVA, J. B. Análise harmônica das precipitações pluviométricas pentadais (Pelotas, RS, 1900-51). Pelotas : UFPel, 1977. 216 p. Tese de Livre Docência.

THIEBAUT, J. T. O emprego da análise harmônica no estudo das precipitações mensais do município de Viçosa-MG. Piracicaba : ESALQ, 1976. 92 p. Dissertação de Mestrado. 